Ramania, B. P., Andayani, T. R, \& Saniatuzzulfa, R. (2019). Peran dukungan sosial pada stres akulturatif mahasiswa asing di Universitas Sebelas Maret. Indigenous: Jurnal Ilmiah Psikologi, 4(2), 118-124. https://doi.org/10.23917/indigenous.v4i2.6530

\title{
Peran Dukungan Sosial pada Stres Akulturatif Mahasiswa Asing di Universitas Sebelas Maret
}

\author{
Bernadeta Pramesi Ramania, Tri Rejeki Andayani, Rahmah Saniatuzzulfa \\ Fakultas Psikologi Universitas Sebelas Maret \\ bernadetramania@gmail.com, menikpsy@staff.uns.ac.id
}

\begin{abstract}
This study aimed to examine the role of social support on international student's acculturative stress in Sebelas Maret University (UNS). A total of 111 students were chosen as population of this quantitative study. Considered by the limited population, previously, the study would be done by the population sampling. Fourthy eight samples were gathered by using incidental sampling and snowball sampling. Acculturative stress scale (Reliability 0,913) and social support scale (reliability 0,855) were used in this study. The result of regression analysis showed that social support significantly has a role on acculturative stress showed by Fcalculated $>$ Ftable $(8,451>4,05)$, p value $0,006(p<0,05)$ and correlation coefficient (R) -0,394. Contribution of the predictor variable to the criterium variabel was $-15,5 \%$. Based on the study results it can be concluded that, social support has $15,5 \%$ negative role on the level of acculturative stress on international student that are learning in UNS.
\end{abstract}

Keywords: acculturative stress; international student; social support; UNS

Abstrak: Penelitian ini bertujuan untuk menguji peran dukungan sosial pada stres akulturatif mahasiswa asing di Universitas Sebelas Maret (UNS). Populasi dalam penelitian kuantitatif ini berjumlah 111 mahasiswa. Subyek dalam penelitian ini berjumlah dengan menggunakan teknik incidental sampling dan snowball sampling. Penelitian dilaksanakan dengan menggunakan skala stres akulturatif (reliabilitas 0,913) dan skala dukungan sosial (reliabilitas 0,855). Hasil teknik analisis regresi sederhana menunjukkan bahwa dukungan sosial berperan pada stres akulturatif secara signifikan ditunjukkan dengan nilai Fhitung > Ftabel $(8,451>4,05)$, nilai p 0,006 $(p<0,05)$ dan koefisien korelasi $(R)$ sebesar $-0,394$. Sumbangan efektif variabel prediktor terhadap variabel kriterium adalah $-15,5 \%$. Berdasarkan hasil penelitian, maka dapat disimpulkan bahwa, dukungan sosial memiliki peran negatif sebanyak 15,5\% pada tingkat stres akulturatif pada mahasiswa asing yang sedang menempuh studi di UNS.

Kata kunci: dukungan sosial; mahasiswa asing; stres akulturatif; UNS

\section{PENDAHULUAN}

Kesadaran akan pentingnya integrasi negara-negara di Asia Tenggara untuk memiliki suatu kawasan bebas perdagangan dalam meningkatkan daya saing ekonomi serta menciptakan pasar regional bagi masyarakat ASEAN membuat negara-negara di ASEAN membentuk kesepakatan untuk membentuk Masyarakat Ekonomi ASEAN (MEA) (Wangke,
2014). MEA menjadi sebuah kesempatan yang baik bagi negara-negara di Asia Tenggara untuk lebih berkembang secara global.

Wangke (2014) juga menyatakan bahwa berbagai hal dilaksanakan dalam merealisasikan visi ini adalah dengan meningkatkan kualitas sumberdaya manusia, sosial, lingkungan hidup, hak cipta intelektual, turisme, keamanan perdamaian, serta adanya hubungan kerjasama yang baik. Sebagai salah satu negara di Asia 
Tenggara, Indonesia telah melakukan berbagai macam internasionalisasi untuk mengikuti perkembangan ini dalam berbagai bidang sehingga membuka kesempatan yang lebih lebar baik bagi mereka yang berkunjung ke Indonesia maupun yang melaksanakan perjalanan ke luar Indonesia.

Upaya peningkatan kualitas sumber daya manusia agar mampu bersaing secara global menjadi salah satu cara yang digunakan oleh berbagai perguruan tinggi di Indonesia dalam mencapai World Class University (Suyanti, 2011). Universitas Sebelas Maret (UNS) merupakan salah satu perguruan tinggi negeri di Indonesia yang menyiapkan diri untuk menghadapi MEA dengan menuju pada World Class University. Hal ini ditandai dengan adanya peningkatan-peningkatan fasilitas kampus dan adanya kelas internasional.

Jumlah mahasiswa asing yang menempuh studi di UNS mengalami peningkatan dan penurunan. Berdasarkan data Biro Administrasi Perencanaan dan Sistem Informasi UNS pada tahun 2015 terdapat 104 mahasiswa asing, tahun 2016 terdapat 105 mahasiswa asing, pada data bulan April tahun 2017 jumlah mahasiswa asing UNS sebanyak 94 mahasiswa dan pada bulan Juli 2017 meningkat menjadi 105 mahasiswa asing. Berdasarkan pada data International Office UNS terdapat peningkatan jumlah mahasiswa asing menjadi 111 mahasiswa asing yang menempuh studi di UNS. Latar belakang mahasiswa asing tersebut berbeda-beda. Sebanyak 64 mahasiswa berasal dari Asia, 15 mahasiswa dari Eropa, 14 mahasiswa dari Afrika, 1 mahasiswa dari Australia dan 5 mahasiswa berasal dari Amerika Utara. Mahasiswa asing yang menempuh studi di UNS ada pada beberapa jenjang pendidikan yaitu: mahasiswa Strata 1, mahasiswa Strata 2, mahasiswa Strata 3, pertukaran mahasiswa, maupun mahasiswa yang masih menempuh pendidikan dasar bahasa Indonesia (BIPA).

Mahasiswaasingyang sedang mengambil program belajar, akan mendapatkan berbagai kesempatan untuk mempelajari kebudayaan yang baru, belajar bahasa yang baru, dan kesempatan untuk berteman dengan berbagai kalangan (Sood, 2012). Selain mendapatkan berbagai kesempatan tersebut mahasiswa asing juga dihadapkan pada berbagai tantangan baik dari lingkungan universitas maupun lingkungan sekitar. Tantangan-tantangan tersebut dapat berasal dari lingkungan sekitar, perbedaan makanan, tradisi, ragam agama, serta tantangan yang berasal dari perbedaan sistem pendidikan di negara tujuan (Rajab, Rahman, Panatik, \& Mansor, 2014). Hal-hal dalam disiplin akademik di perguruan tinggi dapat membingungkan dan misterius bagi individu-individu yang baru terhadap sistem pembelajaran universitas, dan kebingungan ini meningkat terutama pada mahasiswa yang berasal dari latar belakang budaya dan bahasa yang berbeda (Ridley dalam Chen dan Chen, 2009).

Proses belajar untuk menyesuaikan diri pada kebudayaan yang baru membuat baik individu, kelompok, maupun suatu keluarga mengalami berbagai macam stres yang disebut dengan stres akulturatif (Thomas dan Choi, 2006). Stres akulturatif didefinisikan sebagai suatu hasil dari proses akulturasi yang dilakukan oleh mahasiswa asing baik secara langsung maupun tidak langsung dengan aspek sebagai berikut: diskriminasi, homesickness, merasa tidak disukai, rasa takut, dan culture shock (Sandhu dan Asrabadi, 1994). Penelitian yang dilakukan di UNS yang menunjukkan bahwa, hambatanhambatan bagi mahasiswa asing selama melanjutkan studi di UNS adalah perbedaan bahasa, perbedaan persepsi antara mahasiswa asing dan masyarakat lokal, serta adanya stereotip-stereotip dari masyarakat terhadap mahasiswa asing (La'ia, 2016).

Penelitian yang telah dilakukan oleh Thomas dan Choi (2006) menunjukkan bahwa stres akulturatif yang tinggi memiliki hubungan yang erat dengan kurangnya dukungan sosial yang dimiliki oleh individu. Cohen dan Hoberman (1983) mengemukakan bahwa, dukungan sosial merupakan berbagai sumber penopang yang muncul karena adanya hubungan interpersonal antar individu. Cohen dan Hoberman (1983) juga menyatakan bahwa dukungan sosial terdiri dari empat bentuk, yaitu 
appraisal support, tangible support, self esteem support, dan belonging support.

Hovey dan Magana (dalam Desa, Yusooff \& Kadir, 2012) mengatakan bahwa, individu yang mengalami stres akulturatif akan menunjukkan perilaku cemas dan depresi yang dapat meningkat apabila individu tersebut tidak didukung dengan sistem dukungan sosial yang efektif. Mallinckrodt dan Fretz (1988) menyatakan bahwa dukungan sosial menyediakan sumber koping yang kuat pada individu yang mengalami perubahan hidup yang penuh tekanan, termasuk stres dalam proses penyesuaian diri dengan kebudayaan yang baru.

Penelitian mengenai dukungan sosial dan stress akulturatif pada mahasiswa asing telah banyak dilakukan di berbagai negara, UNS, sebagai salah satu universitas yang menuju pada World Class University merupakan salah satu sarana dan kesempatan bagi mahasiswa asing untuk menempuh studi di Indonesia dan juga terutama berinteraksi dengan mahasiswa lokal maupun dengan mahasiswa asing yang juga sedang menempuh studi di UNS. Interaksi ini tentunya akan membuat mahasiswa asing merasakan baik adanya dukungan sosial maupun stress akulturatif seperti yang telah dipaparkan sebelumnya. Berdasarkan hal tersebut rumusan masalah dalam penelitian ini adalah bagaimana peran dukungan sosial pada stres akulturatif mahasiswa asing di UNS?

\section{METODE PENELITIAN}

Pengambilan sampel data pada penelitian ini dilakukan dengan menggunakan teknik sampling yaitu incidental sampling dan teknik sampling snowball dan didapat 48 sampel. Populasi dalam penelitian ini berjumlah 111 mahasiswa asing yang masih aktif berkegiatan di kampus.

Hal tersebut dilakukan karena terdapat beberapa kendala di antaranya: sulitnya mencari kontak mahasiswa asing, beberapa mahasiswa asing sedang tidak aktif berkegiatan di kampus karena penelitian dilakukan selama masa liburan semester, subjek yang aktif di kampus memiliki jadwal yang berbeda-beda tidak mudah untuk ditemui.

Pengambilan data dilakukan dengan dua skala, yakni: skala stres akulturatif dan skala dukungan sosial yang diberikan secara langsung kepada subjek. Skala yang digunakan tersedia dalam dua bahasa yaitu Bahasa Indonesia dan Bahasa Inggris dengan pertimbangan latar belakang mahasiswa asing serta kemampuan bahasa Indonesia yang berbeda-beda.

Skala Stres Akulturatif dalam penelitian ini menggunakan skala yang dikembangkan oleh Sandhu dan Asrabadi (1994) yaitu Acculturative Stress Scale for International Students (ASSIS). Skala ini terdiri dari 36 aitem yang dimodifikasi menjadi 37 aitem oleh peneliti. Modifikasi dilakukan pada aitem nomor 10 "I feel guilty to leave my family and friends behind", yang kemudian dipecah menjadi dua aitem yaitu "I feel guilty to leave my family behind" dan "I feel guilty to leave my friends behind". Peneliti memodifikasi pilihan respon yang pada awalnya memiliki 5 respon yaitu strongly disagree, disagree, not sure, agree, dan strongly agree menjadi 4 pilihan jawaban strongly disagree, disagree, agree, dan strongly agree. Hal ini disebabkan apabila responden cenderung memilih respon not sure, skor skala dapat menjadi bias karena responden tidak memahami butir dan merasa tidak nyaman dengan pertanyaan yang diberikan (Widhiarso, 2010). Hasil uji coba skala menunjukkan terdapat 32 aitem valid dengan Cronbach's Alfa 0,913 .

Dukungan sosial dalam penelitian ini diukur menggunakan skala yang dimodifikasi dari International Support Evaluation List (ISEL) yang disusun oleh Cohen dan Hoberman (1983). Bagian yang dimodifikasi peneliti adalah pilihan respon skala yang pada awalnya definitely false, probably false, probably true, dan definitely true menjadi 4 pilihan jawaban strongly disagree, disagree, agree, dan strongly agree. Hasil uji coba menunjukkan terdapat 22 aitem valid dengan Cronbach's Alfa 0,855. Pilihan jawaban agreedisagree dipilih karena walaupun agree-disagree diartikan sebagai setuju-tidak setuju, namun juga memiliki arti sesuai-tidak sesuai. Agree- 
disagree dirasa lebih mampu merepresentasikan pilihan jawaban skala berbahasa Indonesia (sangat sesuai, sesuai ,tidak sesuai, dan sangat tidak sesuai) dibandingkan dengan kata suit (cocok, sesuai) yang lebih merepresentasikan benda.

Hipotesis diuji dengan analisis regresi sederhana di mana dukungan sosial sebagai variabel prediktor dan stres akulturatif sebagai variabel kriterium.

\section{HASIL DAN PEMBAHASAN}

Analisis regresi untuk penelitian ini dapt dilakukan karena sudah melalui uji prasyarat atau uji asumsi. Beberapa uji yang dilakukan adalah uji normalitas, linearitas, heteroskedastistas, dan uji autokorelasi. Uji normalitas dilakukan dengan one sample Kolmogorov-Smirnov dengan dukungan sosial adalah 0,643 ( $\mathrm{p}>0,05)$ dan stres akulturatif sebesar 0,648 ( $>0,05)$, sehingga dapat diartikan bahwa, data tersebut terdistribusi normal dan memenuhi asumsi normal. Hasil uji linearitas menunjukkan bahwa, Sig. Linearity antara variabel dukungan sosial dan stres akulturatif sebesar $0,001$ ( $\mathrm{p}<0,05)$. Hasil uji heteroskedastisitas menunjukkan penyebaran titik-titik data secara tidak teratur dan tidak membentuk pola tertentu, sehingga dapat disimpulkan bahwa, model regresi dalam penelitian ini tidak memiliki gejala heteroskedastisitas. Hasil Uji Autokorelasi menunjukkan nilai DurbinWatson $1,6231<1,710<2,3769$ sehingga tidak terdapat masalah autokorelasi dalam penelitian ini.

Uji hipotesis dengan menggunakan regresi linier sederhana menunjukkan hasil uji simultan F, Ftabel 8,451>4,05 (Fhitung $>$ Ftabel) dan $p$-value sebesar 0,006 $(\mathrm{p}<0,05)$ sehingga dapat diketahui bahwa terdapat hubungan signifikan antara dukungan sosial dengan stres akulturatif mahasiswa asing di Universitas Sebelas Maret, maka hipotesis dalam penelitian ini diterima. Hasil tersebut membuktikan secara empiris bahwa dukungan sosial memiliki peran terhadap stres akulturatif. Tingginya stres akulturatif berhubungan erat dengan kurangnya dukungan sosial yang diterima (Thomas dan Choi, 2006). Dukungan sosial tidak hanya mampu untuk mengurangi level dari stres akulturatif tetapi juga mampu untuk mengurangi efek dari stres akulturatif tersebut.

Nilai $\mathrm{R}$ sebesar $-0,394$ menunjukkan korelasi berada pada kategori rendah. Nilai R Square sebesar 0,155 menunjukkan bahwa, dukungan sosial memiliki pengaruh kontribusi (sumbangan) sebesar $15,5 \%$ terhadap stres akulturatif dan $84,5 \%$ sisanya dipengaruhi oleh variabel-variabel lain yang tidak diteliti dalam penelitian ini. Hal ini didukung dengan penelitian yang telah dilakukan oleh William dan Berry (1991) yang menunjukkan bahwa fase dari akulturasi yang dialami oleh mahasiswa asing juga merupakan salah satu faktor utama munculnya stres akulturatif. Faktor lain yang dapat mempengaruhi stres akulturatif adalah adanya lingkup sosial yang mempengaruhi proses akulturasi. Williams dan Berry (1991) juga mengatakan bahwa lingkup sosial tersebut berperan sebagai dua faktor penting, yang pertama adalah keterbukaan jaringan komunitas terhadap orang-orang baru dengan memberikan dukungan pada individu yang mengalami proses akulturasi dan yang kedua adalah adanya toleransi dan penerimaan pada perbedaan kebudayaan.

Dukungan sosial yang diterima oleh mahasiswa asing baik dari keluarga dan teman-teman terdekatnya mampu membuat mahasiswa tersebut mampu untuk menghadapi berbagai tantangan yang muncul. Stres akulturatif yang dialami mahasiswa asing dapat memunculkan beberapa respons emosi seperti depresi, kecemasan, alienasi, kebingungan identitas, dan perasaan marginalisasi (Williams dan Berry, 1991). Selama proses tersebut berlangsung, dukungan sosial memiliki peran sebagai perisai untuk menghadapi stres yang muncul dengan cara mencegah satu situasi yang menekan (stressful) dengan memberikan solusi-solusi untuk menghadapi situasi tersebut dan memfasilitasi satu respons sikap yang sehat (Cohen dan Wills, 1985). 
Tabel 1. Hasil Uji Korelasi Parsial Appraisal Support dengan Stres Akulturatif

\begin{tabular}{cccc}
\hline & Nilai korelasi & Nilai Signifikansi & Makna \\
\hline Appraisal & 0,169 & 0,259 & Tidak ada korelasi \\
Belonging support & 0,132 & 0,132 & Tidak ada korelasi \\
\hline
\end{tabular}

Berdasarkan penjelasan di atas, apabila dukungan sosial yang diterima mahasiswa asing tinggi, maka tingkat stress akulturatif yang dirasakan mahasiswa asing rendah. Begitu pula sebaliknya apabila dukungan sosial yang diterima mahasiswa asing rendah, maka tingkat stres akulturatif yang dirasakan oleh mahasiswa asing meningkat.

Kesimpulan ini juga didukung dengan data-data yang ditunjukkan pada tabel distribusi skor aitem skala: pada Subjek 40 dengan total stres akulturatif paling tinggi sebesar 97 yang ditinjau dari dukungan sosial masuk dalam kategori stres akulturatif tinggi, memiliki total dukungan sosial sebesar 59 (kategori rendah), pada Subjek 3 dengan total stres akulturatif sebesar 71 yang termasuk kategori sedang memiliki total dukungan sosial sebesar 58 yang juga berada pada kategori sedang. Subjek 23 yang memiliki skor akulturatif terendah 33 yang masuk dalam kategori rendah, ternyata memiliki skor dukungan sosial sebesar 70 yang termasuk dalam kategori dukungan sosial yang tinggi. Berdasarkan skor tersebut stres akulturatif apabila ditinjau dari dukungan sosial menunjukkan bahwa mahasiswa asing yang memiliki skor dukungan sosial tinggi memiliki skor stres akulturatif yang rendah, sebaliknya skor stres akulturatif tinggi memiliki skor dukungan sosial yang rendah.

Analisis tambahan yang telah dilakukan menunjukkan bahwa tidak ada perbedaan tingkat stress akulturatif berdasarkan jenis kelamin subjek (sig. 0,559>0,05); berdasarkan perbedaan usia (sig. 0,302>0,05); berdasarkan pada jenjang pendidikan (sig. 0,772>0,05); berdasarkan pada benua (sig. 0,556>0,05). Penelitian terdahulu yang dilakukan oleh Desa dkk., (2012) serta penelitian yang dilakukan oleh Misra, Crist, dan Burant (2003) menunjukkan bahwa tidak adanya perbedaan yang signifikan dapat terjadi karena penyesuaian diri terhadap kebudayaan yang baru, termasuk perubahan sikap dan perubahan internal yang lain memiliki pengaruh yang sama terhadap mahasiswa asing tanpa memperhitungkan usia maupun jenis kelamin. Analisis perbedaan skor stres akulturasi berdasarkan pada angkatan mahasiswa asing, juga tidak menunjukkan adanya perbedaan yang signifikan. Analisis terhadap perbedaan jarak kebudayaan (dalam penelitian ini berdasarkan pada asal benua) mahasiswa asing yang menempuh studi di UNS dari berbagai benua memiliki tingkat stres yang tidak terpengaruh oleh jarak kebudayaan. $\mathrm{Hal}$ ini kemungkinan dapat terjadi karena mahasiswa asing yang menempuh studi di UNS telah memahami bahasa Indonesia dasar melalui program BIPA sehingga mahasiswa asing dapat menggunakan bahasa Indonesia dalam kegiatan sehari-hari. Kemampuan berbahasa ini dapat mempermudah dan meningkatkan interaksi dari mahasiswa asing pada mahasiswa lokal maupun pada masyarakat lokal, sehingga mahasiswa asing lebih mampu dalam menghadapi stres akulturatif.

Uji hipotesis dilakukan dengan mencari peran antara ukungan sosial yang berupa appraisal support dan belonging support dengan stres akulturatif dengan uji Anava. Hasil uji anava menunjukkan nilai $\mathrm{F}=4,318$ dan signifikansi sebesar 0,019. Hal ini menunjukkan bahwa kedua bentuk dukungan sosial tersebut berperan secara simultan terhadap stres akulturatif.

Hasil Uji Korelasi Parsial pada hubungan antara appraisal support dan stres akulturatif dengan nilai signifikansi sebesar 0,256 menunjukkan bahwa appraisal support tidak memiliki korelasi dengan stres akulturatif. Analisis Korelasi Parsial yang dilakukan pada belonging support dan stres akulturatif memiliki signifikansi sebesar 0,132 yang menunjukkan bahwa belonging support dan stress akulturatif tidak memiliki korelasi.

Analisis tambahan lainnya adalah dengan uji analisis Kendall Tau untuk menguji 
Tabel 2. Hasil Uji Kendall Tau

\begin{tabular}{cccc}
\hline & Nilai korelasi & Nilai Signifikansi & Makna \\
\hline Tangible support & -0.207 & 0,051 & Tidak ada korelasi \\
Selfesteem support & -0136 & 0,243 & Tidak ada korelasi \\
\hline
\end{tabular}

hubungan pada tangible support dan Self Esteem Support terhadap stress akulturatif Hasilnya adalah signifikansi tangible support terhadap stres akulturatif sebesar 0,51 dan signifikansi Self Esteem Support terhadap stres akulturatif sebesar 0,242 , hal ini menunjukkan bahwa, kedua bentuk tersebut tidak memiliki hubungan yang signifikan dengan stres akulturatif. Hasil analisis tambahan tersebut sesuai dengan penelitian yang telah dilakukan oleh Cohen dan Wills (1985) yang menyatakan bahwa masing-masing bentuk dukungan sosial dapat dibedakan secara teori, namun dalam setting alami bentukbentuk tersebut tidak berdiri secara independen.

\section{SIMPULAN}

Berdasarkan hasil penelitian yang dilakukan pada 48 mahasiswa asing yang menempuh studi di Universitas Sebelas Maret dapat disimpulkan bahwa, dukungan sosial berperan secara positif pada stres akulturatif mahasiswa asing di Universitas Sebelas Maret, sehingga apabila dukungan sosial yang diterima mahasiswa asing semakin tinggi, maka level stres akulturatif yang dialami mahasiswa asing akan semakin rendah.

Analisis tambahan mengenai peran masing-masing bentuk dukungan sosial terhadap stres akulturatif menunjukkan bahwa bentuk dukungan sosial yang berupa appraisal support dan belonging support apabila bekerja secara stimulan mampu untuk mempengaruhi stres akulturatif walaupun dengan sumbangan yang kecil. Namun, saat kedua bentuk tersebut dipisahkan, kedua bentuk tersebut samasama tidak memiliki pengaruh yang signifikan terhadap stres akulturatif. Kemudian, tangible support dan self esteem tidak memiliki korelasi terhadap stres akulturatif apabila tidak bekerja bersamaan dengan appraisal support dan belonging support.

Hasil dari penelitian ini diharapkan dapat dimanfaatkan oleh mahasiswa asing di UNS untuk selalu menjaga komunikasi di lingkaran pertemanan dan keluarga yang mampu memberikan dukungan sosial, sehingga mampu menjadi sarana dukungan dalam menghadapi tekanan-tekanan akademik dan tekanan dari proses adaptasi yang dilakukan, dengan demikian potensi dari mahasiswa asing dapat dioptimalkan

Hasil penelitian ini dukungan sosial memiliki peran negatif sebesar $15,5 \%$ terhadap stres akulturatif, sehingga 84,5\% masih dipengaruhi oleh variabel lain yang tidak diteliti dalam penelitian ini. Saran untuk peneliti selanjutnya agar menggunakan variabel lain yang mempengaruhi stres akulturatif pada mahasiswa asing, misalnya strategi akulturasi yang digunakan oleh mahasiswa asing, kelekatan dengan teman, maupun variabel-variabel lain sehingga penelitian mengenai topik ini dapat berkembang.

\section{REFERENSI}

Chen, Y., \& Chen, H. (2009). A study on international student adjustment from academic, social, and cultural viewpoints in Taiwan. International Conference on Business Management and Information Technology Application, 52-60. Retrieved from https://pdfs.semanticscholar. org/2c06/3b1ae2ae7f206cb5dbe513d5135412252c0c.pdf

Cohen, S., \& Hoberman, H. M. (1983). Positive events and social supports as buffers of life change stress1. Journal of Applied Social Psychology, 13(2), 99-125. https://doi. org/10.1111/j.1559-1816.1983.tb02325.x 
Cohen, S., \& Wills, T. A. (1985). Stress, social support, and the buffering hypothesis. Psychological Bulletin, 98(2), 310-357. https://doi.org/10.1037/0033-2909.98.2.310

Desa, A., Yusooff, F., \& Kadir, N. B. A. (2012). Acculturative stress among international postgraduate students at UKM. Procedia - Social and Behavioral Sciences, 59, 364-369. https://doi. org/10.1016/j.sbspro.2012.09.287

La’ia, J. L. (2016). Adaptasi antarbudaya mahasiswa asing UNS (studi deskriptif kualitatif tentang hambatan komunikasi antarbudaya mahasiswa asing dalam beradaptasi di Solo tahun 2015). Universitas Sebelas Maret. Retrieved from https://digilib.uns.ac.id/dokumen/detail/52238/Adaptasi-Antarbudaya-Mahasiswa-Asing-UNS-Studi-Deskriptif-Kualitatif-tentang-Hambatan-Komunikasi-Antarbudaya-Mahasiswa-Asing-dalam-Beradaptasi-di-Solo-Tahun-2015

Mallinckrodt, B., \& Fretz, B. R. (1988). Social support and the impact of job loss on older professionals. Journal of Counseling Psychology, 35(3), 281-286. https://doi.org/10.1037/00220167.35.3.281

Misra, R., Crist, M., \& Burant, C. J. (2003). Relationships among life stress, social support, academic stressors, and reactions to stressors of International Students in the United States. International Journal of Stress Management, 10(2), 137-157. https://doi.org/10.1037/10725245.10.2.137

Rajab, A., Rahman, H. A., Panatik, S. A., \& Mansor, N. S. (2014). Acculturation stress among international students. Journal of Economics, Business and Management, 2(4), 262-265. https://doi.org/10.7763/JOEBM.2014.V2.136

Sandhu, D. S., \& Asrabadi, B. R. (1994). Development of an acculturative stress scale for international students: preliminary findings. Psychological Reports, 75(1), 435-448. https://doi. org/10.2466/pr0.1994.75.1.435

Sood, S. (2012). The statistics of studying abroad. Retrieved from http://www.bbc.com/travel/story/20120926-the-statistics-of-studying-abroad

Suyanti, E. (2011). Strategi Internasionalisasi dalam Bidang Penelitian pada Universitas Indonesia dan Institut Pertanian Bogor. Jurnal Manajemen Pendidikan, 2(1), 10. https://doi. org/10.21009/jmp.02102

Thomas, M., \& Choi, J. B. (2006). Acculturative stress and social support among Korean and Indian immigrant adolescents in the United States. Journal of Sociology and Social Welfare, 33(2), 123-143. Retrieved from https://scholarworks.wmich.edu/cgi/viewcontent.cgi?article $=3164 \&$ context $=$ jssw

Wangke, H. (2014). Peluang Indonesia dalam masyarakat ekonomi Asean 2015. Info Singkat Hubungan Internasional, VI(10), 5-8. Retrieved from http://berkas.dpr.go.id/pengkajian/files/ info_singkat/Info Singkat-VI-10-II-P3DI-April-2014-4.pdf

Widhiarso, W. (2010). Pengembangan skala psikologi: lima kategori respons ataukah empat kategori respons?, 1-5. Retrieved from http://widhiarso.staff.ugm.ac.id/files/widhiarso_2010_-_respon_alternatif_tengah_pada_skala_likert.pdf 